Journal Economics and Management (JECMA)

Volume 1, No. 02, Februari 2021, p. 1-9

\title{
Pengaruh E-Wom Dan Risk Perception Terhadap Keputusan Berkunjung Wisatawan
}

(Survei pada Pengunjung Gunung Api Purba Nglanggeran)

\author{
The Effect of E-Wom and Risk Perception on Tourist Visit Decisions (Survey on \\ Nglanggeran Ancient Volcano Visitors)
}

\author{
Aditya Solichin*1, Dhea Ayu Resky Amalia ${ }^{2}$, Lily Katniaty ${ }^{3}$, Tri Wisudawati ${ }^{4}$, Ecclisia \\ Sulistyowati ${ }^{5}$, Wahyu Adhi Saputro ${ }^{6}$ \\ ${ }^{1,4}$ Program Studi Teknik Industri, Fakultas Sains dan Teknologi, Universitas Duta Bangsa Surakarta ${ }^{(1)}$ \\ ${ }^{2,6}$ Program Studi Agribisnis, Fakultas Sains dan Teknologi, Universitas Duta Bangsa Surakarta ${ }^{(2)}$ \\ ${ }^{3,5}$ Program Studi Manajemen, Fakultas Hukum dan Bisnis, Universitas Duta Bangsa Surakarta ${ }^{(3)}$ \\ e-mail: ${ }^{1}$ aditsolichin12@gmail.com, ${ }^{2}$ ayudhea@gmail.com. ${ }^{3}$ triwisudawati@gmail.com \\ ${ }^{4}$ wahyu.adhi@gmail.com, ${ }^{5}$ ecclisia_sulistyowati@udb.ac.id, ${ }^{6}$ wahyuadhi@udb.ac.id,6
}

\begin{abstract}
ABSTRAK
Kebutuhan wisata merupakan kebutuhan penting bagi masyarakat yang layak untuk dipenuhi. Wisata yang terlaris dan menjadi favorit adalah wisata alam yang memiliki ketertarikan tersendiri oleh masyarakat. Salah satu wisata alam yang ada di DI Yogyakarta khususnya di Kabupaten Gunungkidul adalah Gunung Api Purba Nglanggeran. Penelitian ini bertujuan untuk mengetahui pengaruh e-Wom dan risk perception terhadap keputusan berkunjung wisatawan di Gunung Api Purba Nglanggeran. Populasi dalam penelitian ini adalah wisatawan yang berkunjung ke tempat wisata di Kabupaten Gunungkidul sedangkan sampel dalam penelitian ini adalah wisatawan yang berkunjung di Gunung Api Purba Nglanggeran. Data yang digunakan dalam penelitian ini adalah data primer yang diambil secara langsung dengan mewawancarai wisastawan dan data sekunder yang berasal dari jurnal, buku dan sumber lain yang masih relevan dengan penelitian ini. Alat analisis yang digunakan dalam penelitian ini adalah analisis regresi linear berganda. Berdasarkan hasil penelitian dapat diketahui bahwa secara bersamasama variabel e-WOM dan risk perception berpengaruh terhadap keputusan berkunjung wisatawan Gunung Api Purba Nglanggeran. Akan tetapi secara parsial hanya variabel e-WOM berpengaruh terhadap keputusan berkunjung wisatawan Gunung Api Purba Nglanggeran.
\end{abstract}

Kata kunci: Wisata, e-WOM, Risk Perception, Keputusan Berkunjung.

\begin{abstract}
Tourism needs are an important need for a community that deserves to be fulfilled. The bestselling and favorite tourism is nature tourism which has its own interest by the community. One of the natural attractions in DI Yogyakarta, especially in Gunungkidul Regency, is the Nglanggeran Purba Volcano. This study aims to determine the effect of e-Wom and risk perception on the decision to visit tourists at Nglanggeran Purba Volcano. The population in this study were tourists who visited tourist attractions in Gunungkidul Regency, while the samples in this study were tourists who visited Nglanggeran Purba Volcano. The data used in this study are primary data which is taken directly by interviewing tourists and secondary data from journals, books and other sources that are still relevant to this research. The analytical tool used in this research is multiple linear regression analysis. Based on the results of the study, it can be seen that together the variables of e-WOM and risk perception have an effect on the decision to visit tourists to the Nglanggeran Purba Volcano. However, only partially the e-WOM variable affects the decision to visit the Nglanggeran Purba Volcano tourists.
\end{abstract}

Keywords: Tourism, e-WOM, Risk Perception, Visiting Decisions.

\section{INTRODUCTION}

Salah satu kebutuhan masyarakat di Indonesia secara umum yang harus dipenuhi adalah kebutuhan untuk berwisata. Hal tersebut memang biasa dilakukan oleh bagian dari masyarakat Indonesia ketika memasuki cuti bersama, libur panjang atau saat weekend. Masyarakat di Indonesia yang memiliki berbagai macam background ekonomi terbiasa untuk melakukan kegiatan wisata dikarenakan hal tersebut adalah kebutuhan dan kebiasaan dengan rerata frekuensi

Submitted: 2021, Accepted: 2021, Published: Februari 2021

ISSN: 2746-0568 (online), Website: http://jurnal.umus.ac.id/index.php/jecma 
Journal Economics and Management (JECMA), Volume 1, No. 02, Februari 2021, p. 1-9

paling sedikit satu kali selama satu tahun. Kebutuhan akan wisata yang cenderung meningkat sehingga banyak wilayah di Indonesia berlomba-lomba memajukan sektor wisatanya terutama pada beberapa tahun terakhir ini. Kementerian Pariwisata mencatakan setidaknya terdapat 251 juta orang yang melakukan wisasta sehingga dapat dikatakan terjadinya hilir mudik yang terjadi dari dan ke tempat wisata. Wisata yang terlaris dan menjadi favorit adalah wisata alam yang memiliki ketertarikan tersendiri oleh masyarakat. Sebagian besar bagian masyarakat sangat tertarik untuk mengunjungi dan beriwsata yang bernuansa alam. Tinginya masyarakat yang berkunjung ke tempat wisata alam disebabkan oleh beberapa hal seperti akses menuju tempat wisata yang sudah baik, tidak ada batasan umur serta wisata alam tersebut dapat dinikmati oleh siapa saja yang mengunjungi. Destinasi wisata alam biasanya juga tidak mematok tiket masuk yang mahal serta tersedianya jalur transportasi umum. Wisata alam biasanya juga tidak hanya menyuguhkan keelokan alam namun terdapat juga sisipan pelajaran religi yang cukup kental di dalamnya. Selain itu wisata alam juga banyak tersedia di bagian wilayah Indonesia[1].

Penghasil devisa negara salah satunya dihasilkan dari sumbangsih sektor pariwisata. Hal tersebut dikarenakan dunia pariwisata mempunyai potensi yang besar untuk maju. Bahkan selain hal itu antar wilayah berlomba-lomba membuat wisata baru di daerah yang dianggap memiliki potensi untuk diwisatakan. Sektor pariwisata yang terkelola dan dikembangankan dengan strategi yang tepat akan memiliki dampak kepada meningkatnya kesejahteraan masyarakat di sekitar area wisata. Selain hal tersebut sektor lain yang dapat ditingkatkan seperti industri rumah tangga yang dapat ditingkatkan seperti kerajinan, home stay dan aneka makanan oleh-oleh. Adanya kerjasama yang baik antara berbagai macam pihak seperti pemerintah, swasta, pengelola wisata akan memajukan wisata tersebut. Dukungan promosi dari berbagai macam pihak melalui media baik cetak maupun elektronik dapat menyebarkan informasi secara luas bahkan bisa mencapai scope internasional. Dengan begitu maka kebutuhan akan teknologi informasi dan komunikasi menjadi perihal penting sebaga sarana promosi wisata[2].

Indonesia memiliki banyak sekali lokasi wisata yang sedang mengalami perkembangan. Hal tersebut juga didukung dengan adanya trend wisatawan yang berkunjung mengalami peningkatan dari tahun ke tahun. Pemaparan data dari BPS tahun 2015 mengungkapkan bahwa kenaikan kunjungan wisata mengalami peningkatan hingga mencapai $34 \%$ jika dibandingkan dengan tahun lalu. Manfaat dari adanya kegiatan pariwisata tersebut disadari oleh pemerintah dengan adanya kenaikan devisa negara serta memiliki peran tersendiri dalam menaikkan kesejahteraan ekonomi masyarakat. Dukungan akan sebab tersebut juga dibuktikan dengan adanya penciptaan lapangan kerja yang dilakukan oleh lokasi wisata terhadap warga sekitar tempat wisata sehingga dapat dijadikan sebagai sarana investasi. Nampaknya hal tersebut mulai dipelajari dan dijadikan sebagai dasar pembangunan sektor wisata pada semua daerah dengan cara mencopy manajemen dan kebijakan wisata tempat lain kemudian di bawa ke lokasi yang akan dijadikan wisata baru hingga media promosi. Selain hal tersebut infrastruktur, sarana dan prasarana juga menjadi komponen pelengkap dalam menunjang sektor pariwisata[3].

Teknologi informasi memudahkan ole pengguna untuk membuat list daerah mana yang akan dikunjungi dengan mengakses dan mendapatkan informasi dari web lokasi wisata. Hal tersebut menjadikan media sebagai sumber utama dalam upaya mencari informasi. Word Tourism Organizations mencatatkan bahwa setidaknya terdapat 95\% pengguna web mengakses internet untuk mengumpulkan informasi mengenai tempat wisata baik wisata baru maupun wisata yang sudah familiar sebelumnya. Angka tersebut sebagian besarnya atau setidaknya sebanyak 93\% digunakan oleh individu untuk mengakses website pariwisata untuk menentukan timeline liburan. Dalam lima tahun terakhir tecatat sejumlah orang atau sebanyak $300 \%$ peningkatan dalam mengakses internet untuk membuat schedule liburan[4]. Dengan begitu dapat diketahui bahwa internet menjadi sarana komunikasi yang penting dalam mengulas tempat wisata dan ditambah dengan adanya komentar netizen yang pernah berkunjung sehingga memperkuat informasi yang ada. Produk wisata yang baik akan berbanding lurus dengan keputusan berkunjung yang semakin tinggi pula. Faktor yang menjadi penting selain hal tersebut agar wisata menjadi maju adalah 
Journal Economics and Management (JECMA), Volume 1, No. 02, Februari 2021, p. 1-9

adanya faktor e-WOM. Maksud dari hal tersebut adalah statement baik positif maupun negatif yang ditunjukkan oleh ulasan orang yang pernah berkunjung pada wisata tertentu sehingga terkesan aktual[4]. Selain adanya hal tersebut tempat wisata pastinya juga mengandung resiko tertentu terutama wisata alam yang penuh dengan rintangan. Hal tersebut diharapkan dapat diminimalisir dengan adanya ulasan tentang destinasi obyek wisata secara umum dan secara khusus sehingga proses pengambilan keputusan pelancong dalam membuat keputusan dan mempersiapkan kebutuhan wisata lebih matang[5].

Pariwisata dunia pada saat ini telah mengalami pergeseran tren. Pergeseran yang dimaksud adalah minat wisatawan yang berubah sehingga lahirnya wisata alam yang membawa pola wisata ekonologis dan wisata minat khusus. Adanya pergeseran tersebut disebabkan oleh beberapa hal seperti adanya minat dan keinginan dari sisi wisatawan yang menginginkan mengunjungi wisata yang memiliki kualitas yang hanya dipandang mata saja namun keinginan mendapatkan pengalaman baru dekat dengan alam[3]. Pergeseran minat wisatawan tersebutlah yang membuat wisata di Gunungkidul menjadi bagian yang menarik untuk dikunjungi.

Potensi wisata yang beragam dimiliki oleh salah satu kabupaten yang ada di Di Yogyakarta yaitu Kabupaten Gunungkidul. Wilayah ini menyediakan keindahan mulai dari pantai hingga gua, air terjun, desa wisata, potensi peninggalan sejarah dan alam. Beragam potensi wisata yang dimiliki daerah tersebut membuat wisatawan menjadi tertarik untuk mengunjungi Gunungkidul. Salah satu primadona andalan yang menjadi daerah wisata di Gunungkidul adalah Gunung Api Purba Nglanggeran. Wisata ini menyuguhkan pegunungan yang membuka mata dengan panorama yang indah, unik, disertai dengan budaya jawa yang melekat di masyarakat sekitar tempat wisata. Hal tesebut juga didukung dengan adanya pelayanan yang ramah dan baik dari pengelola wisata Gunung Api Purba Ngalnggeran sehingga ramai dikunjungi wisatawan. Kawasan Ekowisata ini menyediakan areal pendakian serta menyediakan embung untuk dijadikan tempat kunjungan utama. Wisata ini juga sering dipromosikan menggunakan internet sehingga penyamapain informasi kepada wisata memiliki jangkauan yang luas[6]. Berdasarkan uraian yang sudah dituliskan penelitian ini bertujuan untuk mengetahui pengaruh e-wom dan risk perception terhadap keputusan berkunjung wisatawan.

\section{LITERATURE REVIEW}

\section{Electronic Word of Mouth}

Informasi yang disampakan kepada orang lain oleh suatu individu melalui sebuah proses penyampaian yang baik didefinisikan dengan WOM (Word of Mouth). Informasi yang diberikan akan memberikan pengaruh pada orang lain yang kemudian melakukan keputusan pembelian. Pada dasarnya konsep ini adalah konsep dari mulut ke mulut untuk menyampaikan informasi secara langsung namun pada era saat ini penyampaian informasi tersebut bisa menggunakan media elektronik berupa internet yang dikenal dengan sebutan proses e-WOM. Kesimpulan dari teori tersebut adalah penggunaan media elektronik sebagai media perantara penyampaian informasi sehingga dapat dikatakan bahwa eWOM adalah wujud digital dari WOM[3]. EWOM uga dapat dikatakan sebagai media pemasaran dan komunikasi dengan kandungan isi yang bersifat informatif, positif bahkan bisa juga mengandung informasi negatif yang dilakukan pada pelanggan yang masuk ke dalam segmentasi pasar. Pelanggan dan expelanggan tentunya akan sering melihat berbagai macam produk melalui media internet sehingga besar harapan EWOM dapat menjembatani dalam proses penyampaian informasi agar keduanya melakukan pembelian[7].

Era saat ini menuntut WOM tidak hanya bisa dilakukan secara face to face namun bisa jadi akan ada orang yang menyampaikan informasi namun melakukannya dengan jaringan internet yang kemudian istilah tersebut disebut dengan eWOM[8]. Peningkatan penggunaan internet beberapa tahun teakhir ini sangat menunjang individu dalam mengakses jejaring sosial yang nantinya akan mempengaruhi persepsi seseorang terhadap suatu hal. Dengan begitu dapat 
Journal Economics and Management (JECMA), Volume 1, No. 02, Februari 2021, p. 1-9

dikatakan bahwa penggunaan eWOm akan lebih cepat terserap komunikasi yang diberikan jika dibandingkan dengan WOM di dunia nyata. Hal tersebut juga dikarenakan ada jangkauan yang sangat tinggi yang bisa dilakukan oleh eWOM dalam penyampaian informasi.

\section{Risk Perception}

Pada dasarnya resiko berpengaruh besar dalam pengaruhnya terhadap perilaku konsumen. Risk Perception dipelajari sebagai variabel penjelas dari adanya perilaku konsumen[9][10]. Penelitian mengenai resiko biasanya menyangkut beberapa hal seperti sifat resiko, jenis resiko dan hubungan resiko dengan kelas produk maupun karakter yang terbentuk dari produk tersebut serta pengaruh pengukuran resiko yang dimungkinkan berbeda dari tiap individu. Secara umum belum ada definisi yang bisa diterima terkait resiko dengan perilaku wisata namun pendekatan bisa dilakukan dan digunakan sesuai dengan kebutuhan penelitian yang akan dilakukan. Konstruk mengenai resiko bisa menjelaskan fenomena perilaku konsumsi seperti loyalitas, kepercayaan serta pengambilan keputusan pembelian[11]. Konsep mengenai risiko hanya memfokuskan pada potensi hasil yang negatif saja. Potensi hasil negatif inilah yang akan menjadi perbedaan penting antara pengertian risiko dalam perilaku konsumen dengan pengertian risiko yang digunakan dalam disiplin ilmu lain.

Pada hakikatnya resiko dapat dinilai dari tiga indikator yaitu risiko absolut, risiko yang diterima dan risiko nyata[12]. Dikatakan sebagai absolut jika batasan teratas apabila risiko melekat atau kejadian pada situasi yang tidak diinginkan (tidak ada kontrol kemanan). Risiko nyata adalah banyaknya resiko yang ada saat waktu tertentu disesuaikan dengan tingkat kemanan yang ada. Sementara itu resiko yang diterima adalah resiko yang muncul secara subhektif dari individu yang muncul dari risiko nyata setiap waktu. Lebih jauh dijelaskan bahwa, tingkat yang diinginkan dari resiko konsumen dapat berupa lebih besar dari atau kurang dari risiko yang dirasakan. Apabila dikaji ketrrkaitan antara berbagai resiko yang muncul maka keterkaitan antara risiko yang dirasakan dan risiko yang diinginkan tidak hanya akan mempengaruhi perilaku pembelian konsumen, tetapi juga dapat mempengaruhi perilaku konsumen di perjalanan jika mereka mencari risiko yang lebih besar (di mana risiko yang diinginkan > dirasakan resiko) atau jika mereka mencari risiko lebih kecil (di mana diinginkan risiko < risiko yang dirasakan). Risiko merupakan komponenn penting yang dibutuhkan informasinya oleh konsumen. Wisatawan terdorong akan dengan sendirnya mencari tambahan informasi ketika ingin membeli produk dengan resiko tinggi[13]. Persepsi tinggi pada resiko akan memotivasi penghindaran pembelian serta meminimalkan risiko dengan cara pencarian evaluasi alternatif setelah membeli produk ketika melakukan pengambilan keputusan[14].

\section{Keputusan Berkunjung}

Pengambilan keputusan yang dilakukan oleh individu didasarkan pada tahapan evaluasi disertai pertimbangan yang matang ketika merencanakan sesuatu untuk melakukan kunjunga ke objek wisata tertentu[15]. Analogi yang tepat dalam membahas keputusan berkunjung merupakan konsep keputusan pembelian terhadap produk maupun jasa yang dibutuhkan dengan dasar keleluasaan. Individu yang memutuskan untuk berkunjung ke tempat wisata dengan niat membeli produk dalam hal ini yang dimaksud wisata merupakan produk yang hanya dapat dirasakan namun tidak dapat dipegang. Pada dasarnya konsep kunjungan wisatawan tidak hanya ketika berada di tempat wisata namun juga secara tidak langsung merupakan perjalan menuju wilayah tersebut yang merupakan bagian dari satuan wisata yang harus dibayar oleh konsumen. Terdapat lima fase penting yang dilalui oleh individu dalam melakuan proses pengambilan keputusan diantaranya adalah persiapan perjalanan, pengalaman wisata, evaluasi, perjalanan dan pencarian informasi[2]. Hal tersebut juga senada dengan pernyataan bahwa pengambilan keputusan dilakukan dalam lima tahapan seperti pengenalan kebutuhan, pencarian informasi, evaluasi alternative pilihan, keputusan pembelian, dan perilaku pasca pembelian[1]. 
Journal Economics and Management (JECMA), Volume 1, No. 02, Februari 2021, p. 1-9

\section{METHODS}

Penelitian ini merupakan penelitian yang menggunakan metode deskriptif analitik. Pemilihan lokasi wisata di Gunung Api Purba Ngelanggeran menggunakan purposive dikarenakan wisata ini merupakan wisata alam terdekat yang ada di Gunungkidul sehingga merupakan alternatif kunjungan utama wisatawan ketika ke Gunungkidul. Data yang digunakan dalam penelitian ini terdiri dari dua sumber data yaitu data primer dan data sekunder. Data primer merupakan data yang diambil secara langsung dengan mewawancarai responden yang dianggap representatif dalam penelitian ini. Dalam mengambil sampel penelitian menggunakan convenience sampling. Hal tersebut dikarenakan metode tersebut mudah dilakukan dan memiliki peluang yang besar bagi anggota populasi untuk terpilih sehingga memudahkan peneliti. Responden dihitung berdasarkan jumlah pengunjung yang mengunjungi wisata Gunung Api Purba. Secara matematis perhitungan tersebut dituliskan dalam persamaan berikut ini:

Keterangan:

$$
n=\frac{N}{1+N e^{2}}
$$

$\mathrm{n}=$ Ukuran sampel

$\mathrm{N}=$ Ukuran populasi

$\mathrm{e}=$ Nilai Kritis

Berdasarkan data sekunder jumlah pengunjung wisata Gunung Api Purba pada tahun 2020 sebesar 108.317 orang. Margin error yang digunakan dalam penelitian ini sebesar 10\%. Dari hasil perhitungan sampel yang diambil adalah 99,93 akan tetapi dalam penelitian ini akan digunakan sebanyak 100 responden yang dijadikan sampel. Analisis yang dilakukan dalam penelitian ini menggunakan analisis regresi linera berganda dengan dua variabel independen yaitu e-WOm dan risk perception sementara itu variabel dependen adalah keputusan berkunjung wisatawan. Secara matematis dapat dituliskan pada persamaan berikut ini:

dimana:

$$
Y=\beta_{0}+\beta_{1} X_{1}+\beta_{2} X_{2}+e
$$

$$
\begin{array}{ll}
\mathrm{Y} & =\text { Keputusan Berkunjung } \\
X_{1} & =\text { eWOM } \\
X_{2} & =\text { Risk Perception } \\
\beta_{0} & =\text { Konstanta } \\
\beta_{1,2} & =\text { Koefisien regresi } \\
e & =\text { Error }
\end{array}
$$

\section{RESULTS AND DISCUSSION}

Sebelum data memasuki uji regresi linear berganda alangkah lebih baiknya jika data melewati beberapa uji seperti uji normalitas, uji multikolineritas dan uji heterokedastisitas. Apabila data sudah melalui ketiganya dan dinyatakan lolos terhadap uji tersebut maka dapat dikatakan data sudah baik dan layak untuk diuji regresi linear berganda. Berikut ini adalah uji pertama yang dilakukan yaitu uji normalitas.

Pada gambar 1 dapat diketahui bahwa uji normalitas data yang digunakan dalam penelitian ini. Uji normalitas data diperuntukan agar dapat diketahui apakah data yang digunakan dalam penelitian ini mengikuti distribusi normal atau tidak. Hal tersebut dilihat dari variabel yang digunakan dalam penelitian ini baik dari variabel dependen maupun variabel independennya. Data dikatakan baik apabila mengikuti kaidah distribusi normal sehingga ketika data digunakan dan diintepretasikan tidak bias. 
Journal Economics and Management (JECMA), Volume 1, No. 02, Februari 2021, p. 1-9

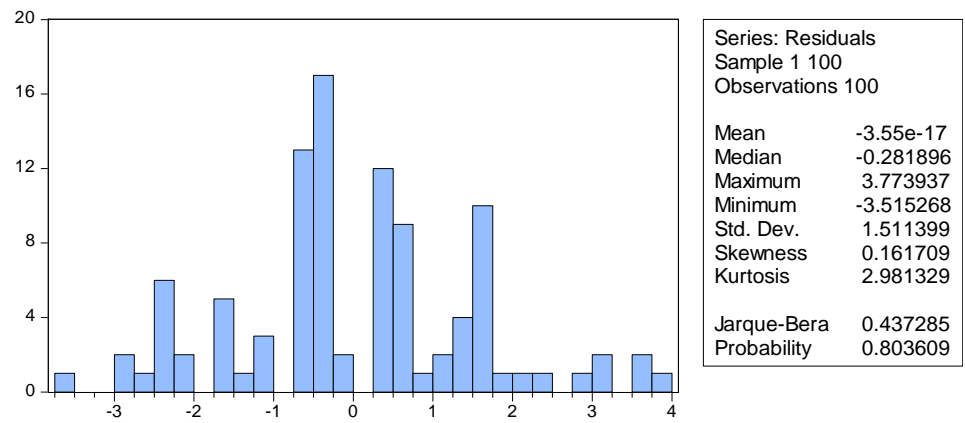

Gambar 1. Uji Normalitas

Sumber: Analisis Data Primer, 2020

Berdasarkan gambar 1 dapat dilihat indikator pengujian normalitas pada probabilitas nilai Jarque bera yang menunjukkan angka 0,80 . Apabila nilai tersebut lebih besar dari nilai alpha 0,05 persen maka dapat disimpulkan bahwa data mengikuti kaidah distribusi normal dan baik untuk digunakan. Uji normalitas juga harus diikuti uji lanjutan sebelum memasuki uji analisis regresi berganda yaitu uji multikolinearitas yang dapat dilihat pada tabel 1 .

Table 1. Uji multikolinearitas

\begin{tabular}{cc}
\hline Variable & VIF \\
\hline $\mathrm{X} 1$ & 2.033466 \\
\hline $\mathrm{X} 2$ & 2.03346 \\
\hline Sumber: Analisis Data Primer, 2020 &
\end{tabular}

Berdasarkan tabel 1 dapat diketahui indikator pengujian multikolinearitas yang diwujudkan pada nilai VIF. Secara kaidah apabila nilai VIF kurang dari 10 maka dapat dikatakan bahwa data yang digunakan dalam penelitian ini lolos uji multikolinearitas. Pada dasarnya uji ini digunakan untuk melihat apakah data yang digunakan dalam penelitian terdapat korelasi atau tidak. Berdasarkan tabel 1 dapat diketahui bahwa kedua nilai VIF kurang dari 10 yaitu sebesar 2,033 sehingga keduanya lolos dari uji multikolinearitas. Setelah uji multikolinearitas maka harus dilanjutkan dengan uji heterokedastisitas yang dapat dilihat pada tabel 2.

Table 2. Uji heterokedastisitas

\begin{tabular}{llll}
\hline F-statistic & 0.137965 & Prob. F(2,67) & 0.8714 \\
\hline Obs*R-squared & 0.287104 & Prob. Chi-Square(2) & 0.8663 \\
\hline Scaled explained SS & 0.222893 & Prob. Chi-Square(2) & 0.8945 \\
\hline Sumber: Analisis Data Primer, 2020 & &
\end{tabular}

Berdasarkan tabel 2 mengenai uji multikolinearitas dapat dilihat dari indikator nilai probabilitas Obs*R-squared sebesar 0,866. Nilai tersebut berada atau lebih besar dari nilai alpha $5 \%$ sehingga dapat disimpulkan bahwa data yang digunakan dalam penelitian ini lolos dari uji heterokedastisitas. Uji ini pada hakikatnya diperuntukkan untuk melihat apakah Model regresi dimungkinkan terjadi ketidaksamaan varian dari residual satu ke pengamatan lainnya sehingga data perlu melalui pengujian heterokedastisitas. Jika data sudah lolos dari uji normalitas, uji heterokedastisitas dan multikolinearitas maka dapat dilanjutkan pada uji analisis regresi linear berganda.

Bedasarkan tabel 3 mengenai hasil analisis regresi berganda dapat dilihat bahwa nilai adj $R$ Squared sebesar 0,3460 sehingga dapat dikatakan bahwa variasi dari variabel dependen yaitu keputusan berkunjung dapat dijelaskan oleh variabel independen yang tertera pada model regresi 
Journal Economics and Management (JECMA), Volume 1, No. 02, Februari 2021, p. 1-9

yaitu e-WOM dan risk perception sebanyak 34,60\%. Sisanya sebanyak 65,40 dijelaskan oleh variabel lain yang tidak diikutkan di dalam model regresi linear berganda.

Table 3. Analisis linier berganda

\begin{tabular}{lcccc}
\hline \multicolumn{1}{c}{ Variable } & Coefficient & Std. Error & t-Statistic & Prob. \\
\hline X1 & 0.133803 & 0.040569 & 3.298141 & 0.0016 \\
\hline X2 & 0.062811 & 0.047038 & 1.335322 & 0.1863 \\
\hline C & 2.985189 & 1.686787 & 1.769749 & 0.0813 \\
\hline R-squared & 0.365014 & Mean dependent var & 12.78571 \\
\hline Adjusted R-squared & 0.346060 & S.D. dependent var & 1.824891 \\
\hline S.E. of regression & 1.475727 & Akaike info criterion & 3.658090 \\
\hline Sum squared resid & 145.9106 & Schwarz criterion & 3.754455 \\
\hline Log likelihood & 125.0332 & Hannan-Quinn criter. & 3.696367 \\
\hline F-statistic & 19.25710 & Durbin-Watson stat & 1.912384 \\
\hline Prob(F-statistic) & 0.000000 & &
\end{tabular}

Jika melihat nilai dari hasil uji F yang tertera pada Prob(F-statistic) memiliki nilai 0,00 dan nilai tersebut kurang dari alpha 5\%. Hal tersebut berarti bahwa secara bersama-sama variabel independen yang digunakan dalam penelitian ini yaitu e-WOM dan risk perception mampu mempengaruhi keputusan berkunjung wisatawan di Gununng Api Purba Nglanggeran. Jika melihat dari uji parsial atau uji-t dapat diketahui bahwa hanya satu variabel independen yang mampu mempengaruhi variabel dependen. Variabel yang mempengaruhi tersebut adalah variabel X1 (e-WOM). Sementara itu variabel X2 (risk perception) tidak berpengaruh terhadap keputusan berkunjung. Hal tersebut tercermin dari nilai signifikansi t pada variabel $\mathrm{X} 1$ yang menunjukkan nilai 0,0016 atau kurang dari alpha 0,05 sedangkan nilai signifikansi t pada variabel X2 lebih dari nilai alpha 5\% sehingga tidak mempengaruhi variabel dependen keputusan berkunjung. Hal tersebut senada dengan penelitian Mustikasari dan Widianingsih [18] yang menyatakan bahwa eWOM berpengaruh terhadap keputusan berkunjung wisata dan mampu mempengaruhi calon wisatawan untuk menentukan tempat tujuan wisata yang akan dia kunjungi di Kota Bandung baik secara parsial maupun simultan. Tingginya e-WOM maka akan menguatkan sisi berkunjung dari wisatawan yang ingin berkunjung di Gunung Api Purba Ngelanggeran. Jika wisatawan sudah mengumpulkan informasi terlebih dahulu sebelum berkunjung dan reaksi wisatawan ketika mengunjungi tempat tersebut dan realitanya sama persis dengan harapan para wisatawan akan berujung pada kepuasan yang disebabkan oleh kualitas yang ada pada pemberian informasi eWOM. Intinya kepuasan adalah akibat dari kualitas yang diberikan [19]. Pada akhirnya seorang konsumen yang memutuskan untuk membeli atau menggunakan jasa memang harus melalui tahap demi tahap [20]. Tahapan yang dimaksud memang dimulai dari perencanaan matang dengan menggali informasi sebanyak mungkin (e-WOM) hingga memutuskan untuk berkunjung ke Gunung Api Purba Nglanggeran.

\section{CONCLUSION}

Berdasarkan hasil penelitian dapat diketahui bahwa secara bersama-sama variabel e-WOM dan risk perception berpengaruh terhadap keputusan berkunjung wisatawan Gunung Api Purba Nglanggeran. Akan tetapi secara parsial hanya variabel e-WOM berpengaruh terhadap keputusan berkunjung wisatawan Gunung Api Purba Nglanggeran. Melihat hasil tersebut maka sebaiknya pengelola wisata Gunung Api Purba Nglanggeran lebih mengintensifkan manajemen e-WOM dengan cara membuat website dan media sosial secara khusus membahas objek wisata Gunung Api Purba dan info yang diberikan agar up to date sehinga tidak terjadi simpang siur informasi. 
Journal Economics and Management (JECMA), Volume 1, No. 02, Februari 2021, p. 1-9

\section{REFERENCES}

[1] A. Mustikasari and S. Widaningsih, "Pengaruh E-Wom Terhadap Keputusan Berkunjug Ke Tempat Wisata Di Kota Bandung," J. Manaj. Indones., vol. 16, no. 2, pp. 95-103, 2016, doi: https://doi.org/10.25124/jmi.v16i2.315.

[2] H. Susilawati, "Pengaruh Electronic Word of Mouth Terhadap Keputusan Berkunjug di Sindu Kusuma Edupark," J. Khasanah Ilmu, vol. 8, no. 2, pp. 32-38, 2017, doi: https://doi.org/10.31294/khi.v8i2.2297.

[3] A. Widyanto, S. Sunarti, and E. Pangestuti, "Pengaruh E-Wom Di Instagram Terhadap Minat Berkunjung Dan Dampaknya Pada Keputusan Berkunjung," J. Adm. Bisnis, vol. 45, no. 1, pp. 94-101, 2017.

[4] C. H. Chen, B. Nguyen, P. "Phil" Klaus, and M. S. Wu, "Exploring Electronic Word-ofMouth (eWOM) in The Consumer Purchase Decision-Making Process: The Case of Online Holidays - Evidence from United Kingdom (UK) Consumers," J. Travel Tour. Mark., vol. 32, no. 8, pp. 953-970, 2015, doi: 10.1080/10548408.2014.956165.

[5] F. Di Virgilio and L. Di Pietro, "Tourist' s Group Knowledge Representation and the Role of E-Wom for the Choice of Tourist Destination," Athens J. Tourusm, vol. 1, no. 1, pp. 920, 2005, doi: doi.org/10.30958/ajt.1-1-1.

[6] A. Hasan and N. W. Setiyaningtiyas, "Pengaruh Electronic Word of Mouth Pada Media Sosial Facebook Terhadap Keputusan berkunjung Ke Desa Wisata Nglanggeran Gunungkidul," J. Media Wisata, vol. 13, no. 1, 2015, doi: https://doi.org/10.36276/mws.v13i1.80.

[7] N. Sa'ait, A. Kanyan, and M. F. Nazrin, "The Effect of E-WOM on Customer Purchase Intention.," Int. Acad. Res. J. Soc. Sci., vol. 2, no. 1, pp. 73-80, 2016.

[8] S. Sanchez-Cañizares and M. Castillo-Canalejo, "A comparative study of tourist attitudes towards culinary tourism in Spain and Slovenia," Br. Food J., vol. 117, no. 9, 2015, doi: dx.doi.org/10.1108/BFJ-01-2015-0008.

[9] L. J. Liang, H. S. C. Choi, and M. Joppe, "Understanding repurchase intention of Airbnb consumers : perceived authenticity, electronic word-of-mouth, and price sensitivity," $J$. Travel Tour. Mark., vol. 00, no. 00, pp. 1-17, 2017, doi: 10.1080/10548408.2016.1224750.

[10] S. D'Alessandro, A. Girardi, and L. Tiangsoongnern, "Perceived risk and trust as antecedents of online purchasing behavior in the USA gemstone industry," Asia Pacific J. Mark. Logist., vol. 24, no. 3, pp. 433-460, 2012, doi: 10.1108/13555851211237902.

[11] H. Chahal and A. Devi, "Destination Attributes and Destination Image Relationship in Volatile Tourist Destination: Role of Perceived Risk," Metamorph. A J. Manag. Res., vol. 14, no. 2, pp. 1-19, 2015, doi: 10.1177/0972622520150203.

[12] S. (Sam) Kim, J. Y. Chung, J. Petrick, and J. W. Park, "Determination of preferred performing arts tourism products using conjoint analysis," J. Vacat. Mark., vol. 24, no. 1, pp. 44-61, 2018, doi: 10.1177/1356766716679484.

[13] G. Maciejewski, "The Meaning of Perceived Risk In Purchasing Decisions of The Polish Customers," J. Tour. Futur., vol. 2, no. 1, 2012.

[14] N. retno Hapsari, N. Lubis, and Widiartanto, "Pengaruh pengaruh atribut produk wisata dan electronic word of mouth (ewom) terhadap keputusan berkunjung pada obyek Wisata Umbul Sidomukti Kabupaten Semarang," J. Ilmu Adm. Bisnis, vol. 3, no. 4, pp. 249-259, 2014, [Online]. Available: http://jateng.tribunnews.com.

[15] E. Fitriana, "Strategi Pengembangan Taman Wisata Kum Kum Sebagai Wisata Edukasi Di Kota Palangkaraya," J. Pendidik. Geogr., vol. 23, no. 2, pp. 94-106, 2018, doi: 10.17977/um017v23i22018p094. 